\title{
MURCS association: case report and review
}

\author{
Cordula Braun-Quentin, Christiane Billes, Bernhard Böwing, Dieter Kotzot
}

Institute of Human

Genetics, University of Erlangen-Nürnberg, Schwabachanlage 10, 91054 Erlangen,

Germany

C Braun-Quentin

Ch Billes

D Kotzot

Children's Hospital, University of Erlangen-Nürnberg, 91504 Erlangen,

Germany

B Böwing

Correspondence to: Dr Kotzot.

Received 12 September

1995 publication 8 February 1996
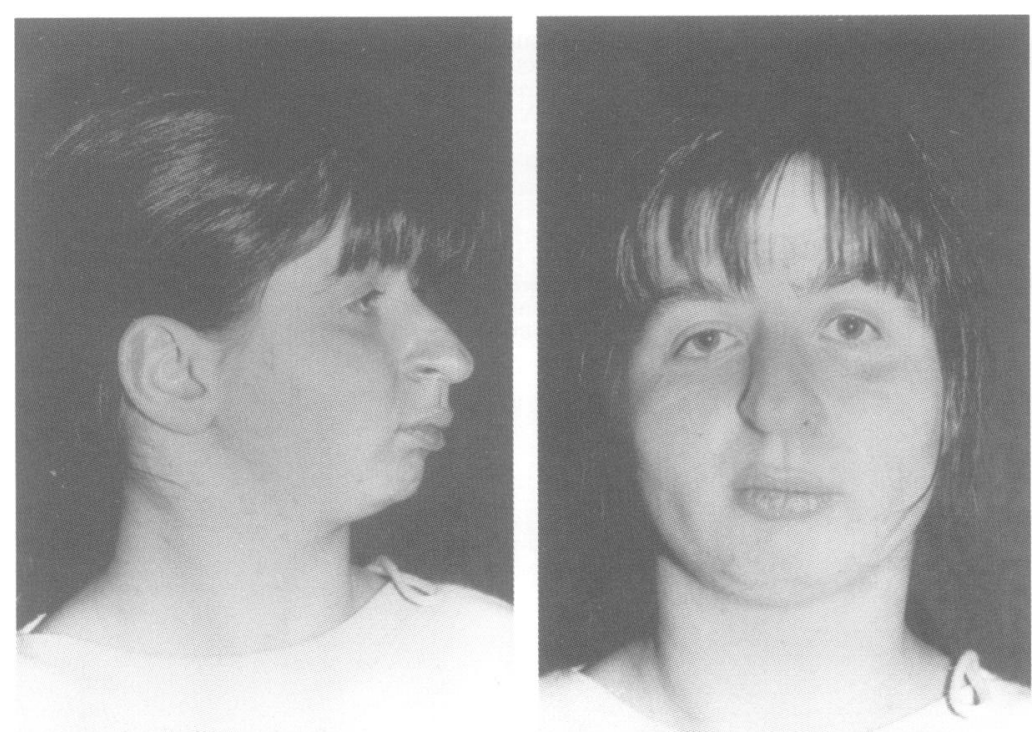

Figure 1 Note facial asymmetry with normal ears at the age of 25 years. pregnancy was uneventful and delivery was at term. Birth weight $(2750 \mathrm{~g})$ and length $(50 \mathrm{~cm})$ were within the normal range. The right kidney was absent and contralateral hydronephrosis required kidney transplantation in childhood.

On examination height was $152 \mathrm{~cm}$ (3rd centile), weight was $55 \mathrm{~kg}$ ( $50 \mathrm{th}$ centile), and occipitofrontal circumference was $58 \mathrm{~cm}$ (97th centile). Endocrinological investigations, karyotyping, psychomotor development, and secondary sexual characteristics were unremarkable. Laparoscopy displayed histologically normal but macroscopic cystic ovaries, a rudimentary uterus duplex, and a cord-like vagina without any lumen.

Facial asymmetry was obvious (fig 1). Both ears were normal in shape, location, and function. The teeth were unremarkable. $X$ rays of the spine showed subtotal fusion of $\mathrm{C} 2$ and $\mathrm{C} 3$, hemivertebra $\mathrm{C} 7$, and bilateral $\mathrm{C} 7$ cervical ribs partly fused with the first thoracic ribs (fig 2). Bone age corresponded to the chronological age.

Aplasia of the Müllerian duct is also called Mayer-Rokitansky-Küster-Hauser (MRKH) syndrome. Strübbe $e t$ al ${ }^{18}$ found 13 cases with MURCS association out of 56 women with atypical MRKH syndrome, but none out of 44 women with typical MRKH syndrome.

Dysplasia of the cervical somites is also called Klippel-Feil sequence. Associated anomalies of the musculoskeletal, neurological, cardiovascular, and genitourinary system have been described, ${ }^{19}$ but only one woman had in addition an anomaly of the upper urinary tract and vaginal agenesis with a bicornuate uterus. ${ }^{20}$

The aetiology of MURCS association is not known. The karyotype was normal in all investigated cases and so far all cases have been sporadic. Therefore, autosomal recessive inheritance is unlikely. $\mathrm{X}$ linked inheritance would require a more severe or even lethal phenotype in males. In autosomal dominant inheritance, only fathers would be affected, because reproduction in females is not possible.

In males aplasia/hypoplasia of the Müllerian duct should not have any functional consequence, since only the cranial and the caudal ends persist, the first as the appendix testis, the other as the uterus masculinus in the prostate. ${ }^{21}$ Wellesley and Slaney ${ }^{22}$ reported on a man with left renal agenesis, block fusion from C6-T8 with multiple deformities of several neural arches, azoospermia, and normal chromo- 


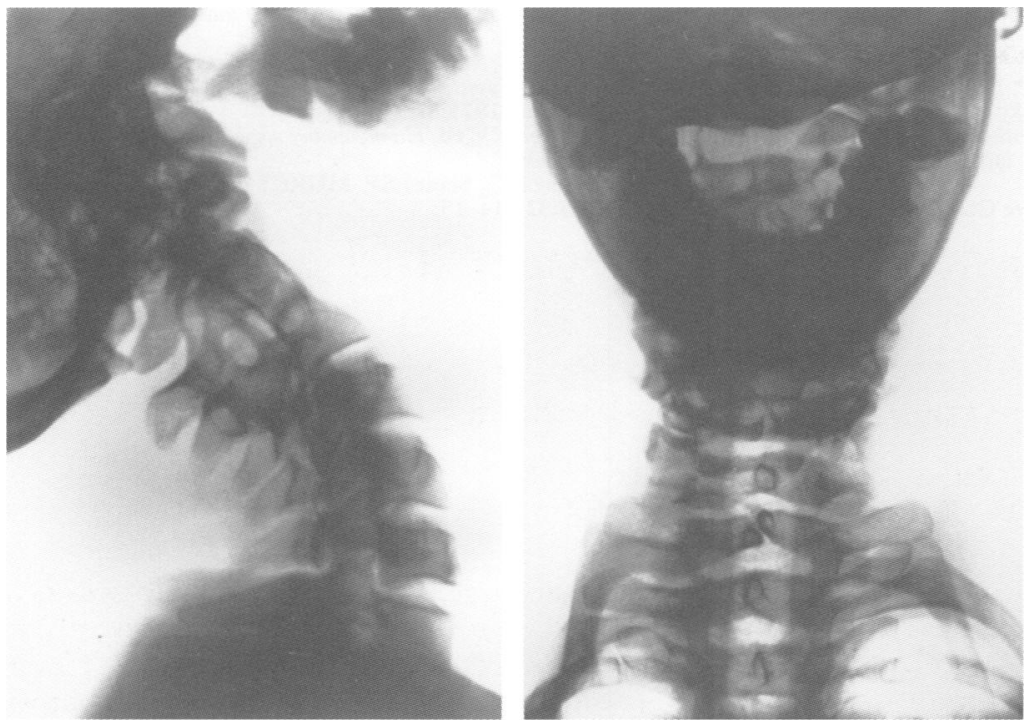

Figure $2 X$ ray of the cervical column with C2-3 fusion and C7 hemivertebra, as well as bilateral $C 7$ cervical ribs in part fused with the first thoracic ribs.

somes. Both epididymi were present, the testes were small and soft, and the vasa deferentia (descendents of the Wolffian duct) were thin. The authors assumed that this was MURCS in a man, and proposed the acronym WORCS (Wolffian duct aplasia/hypoplasia, renal agenesis, and dysplasia of the cervicothoracic somites).

Exposure to an unknown teratogenic agent at the end of the fourth fetal week has been assumed. ${ }^{1}$ At this time blastemata of the lower cervical (C3-C5) and upper thoracic somites, as well as the pronephric ducts, are closely related. The latter turns the Wolffian duct and induces the mesonephron and the Müllerian duct, formed between day 44 and 56 of embryonic development by invagination of the coelom. In females, fallopian tubes develop from the distal part of the Müllerian duct, fundus and corpus uteri from the proximal part, and cervix uteri as well as the upper two thirds of the vagina from the lowest part, also called canalis uterovaginalis. ${ }^{21}$ Therefore, any disturbance at the end of the fourth fetal week might influence the development of vertebrae, kidneys, and descendants of the Müllerian duct.

The broad spectrum of associated anomalies, the involvement of different organ systems closely related in early embryogenesis, and sporadic occurrence are strong arguments to consider MURCS association as a developmental field defect. Moreover, the spatial relation of the cervical somites and the pronephric duct at the end of the fourth fetal week and the following cascade-like induction of renal development fulfil the criteria of a developmental field.

Differential diagnosis of MURCS association includes Goldenhar syndrome, VACTERL association, and Turner's syndrome. VACTERL association is rarely combined with genital anomalies and vertebral malformations are located more often in the caudal region. In Goldenhar syndrome urogenital abnormalities are rare. ${ }^{19}$
Various other anomalies have been described frequently in women with MURCS association. ${ }^{1-3579-1113-17}$ Abnormalities of the upper extremities or thoracic ribs, scoliosis, and facial asymmetry can be attributed to the dysplasia of the cervical somites. Encephalocele, hearing loss, corneal anaesthesia, cleft lip/palate, or malformations of the central nervous system are rare and might be by chance. ${ }^{145812}$ Renal problems as in our case often result in growth retardation as a secondary symptom.

In the original report of Duncan et al ${ }^{1}$ uterine aplasia/hypoplasia, renal agenesis/ectopy, and anomalies of the cervical spine were only present in 16 out of 30 cases. Only 46 out of 65 previously published cases have had all three major manifestations. Therefore, the acronym MURCS should be restricted to women with all typical symptoms. Application to patients with only some of the typical manifestations is confusing and hinders the delineation from atypical cases of Klippel-Feil sequence, $\mathrm{MRKH}$ syndrome, or Goldenhar syndrome.

In conclusion, MURCS association should be considered as a developmental field defect and only diagnosed if both aplasia/hypoplasia of the Müllerian duct, renal agenesis/ectopy, and anomalies of the cervicothoracic somites are present.

1 Duncan PA, Shapiro LR, Stangel JJ, Klein RM, Addonizio JC. The MURCS association: müllerian duct aplasia, renal aplasia, and cervicothoracic somite dysplasia. $\mathcal{f}$ Pediatr 1979;95:399-402

2 Boutroy JL, Manini P, Girard M, Ribon M. Syndrome de Rokitansky-Küster-Hauser atypique et dysmorphies turneriennes a caryotype normal (syndrome d'UllichNoonan). $¥$ Gynecol Obstet Biol Reprod 1978;7:831-5.

3 Colavita N, Orazi C, Logroscino C, Dell'Acqua G, La Vecchia G. Does MURCS association represent an actual nonrandom complex of malformations? Diagn Imag Clin Med 1986;55:172-6.

4 Esakowitz L, Yates JRW. Congenital corneal anaesthesia and the MURCS association: a case report. $B r f$ Ophthal 1988;72:236-8.

5 Green RA, Bloch MJ, Huff DS, Iozzo RV. MURCS association with additional congenital anomalies. Hum Pathol 1986;17:88-91.

6 Heidenreich W. Genital und extra-genital Fehlbildungen beim Mayer-Rokitansky-Küster Syndrom. Dtsch Med Wochenschr 1988;173:1092-6.

7 Iudice LG, Federico P, Pasquali D, Petrenga E, Schilliro F, D'Alessandro B. The MURCS association. Clinical, radiological, endocrinological and familial data in a $40-$ radiological, endocrinological and familial data in a

8 Lin HJ, Cornford ME, Hu B, Rutgers JKL, Beall $\mathrm{MH}$, Lachman RS. Occipital encephalocele and MURCS association: case report and review of central nervous system anomalies in MURCS patients. Am $\mathcal{F}$ Med Genet 1995;61:59-62.

9 Mahaj an P, Kher A, Khungar A, Bhat M, Sanklecha M, Bharucha BA. MURCS association - a review of 7 cases. f Postgrad Med 1992;38:109-11.

10 Mendez PJ, Ulloa-Aguirre A, Sanchez FJ, Mutchinick O, Perez-Palacios G. Endocrine evaluation in a patient with MURCS association and ovarian agenesis. Eur $\mathcal{F}$ Obstet Gynecol Reprod Biol 1986;22:161-9.

11 Mendez PJ, Orozco M, Ruiz AI, Orozco E, Diaz L. MURCS association and hypothalamic anovulation. Rev Invest Clin 1992;44:115-21.

12 Örstavol $\mathrm{KH}$, Steen-Johnson J, Foerster A, Fjeld $\mathrm{T}$, Skullerud K, Lie SO. VACTERL or MURCS association in a girl with neurenteric cyst and identical thoracic ation in a girl with neurenteric cyst and identical thoracic malformations in the father: a case of gonosomal mo-

13 Strübbe EH, Cremers CWRJ, Willemsen WNP, Rolland R, Thjin CJP. The Mayer-Rokitansky-Küster-Hauser (MRKH) syndrome without and with associated feature: two separate entities? Clin Dysmorphol 1994;3:192-9.

14 Vaidya VU, Sidhva SJ, Bharucha BA, Kagalwala TY, Kumta NB. MURCS association. Indian Pediatr 1987;24:588-92.

15 Willemsen WNP. Combination of the Mayer-RokitanskyKüster and Klippel-Feil syndrome. Eur $\mathcal{F}$ Obstet Gynecol Reprod Biol 1982;13:229.

16 Willemsen WNP. Renal-skeletal-ear and facial anomalies in combination with the Mayer Rokitansky Küster syndrome. Eur F Obstet Gynecol Reprod Biol 1982;14:121-30.

17 Winer-Muram HT, Muram D, Wilroy RS, Cupp C. The 
concurrence of facioauriculovertebral spectrum and the Rokitansky syndrome. Am f Obstet Gynecol 1984;149: 569-70.

18 Strübbe EH, Willemsen WNP, Lemmens JAM, Thijn CJP, Rolland R. Mayer-Rokitansky-Küster-Hauser syndrome: distinction between two forms based on excretory, urodistinction between two forms based on excretory, uro-
graphic, sonographic, and laparoscopic findings. $A f R$

19 Cohen MM, Rollnick BR, Kaye CI. Oculoauriculovertebral spectrum: an update critique. Cleft Palate $\mathcal{F} 1989 ; 26: 276-$

20 Moore WB, Matthews TJ, Rabinowitz R. Genitourinary anomalies associated with Klippel-Feil syndrome. $\mathcal{f}$ Bone foint Surg 1975;57:355-7.

21 Hinrichsen KV, ed. Humanembryologie. Berlin: Springer Ver-

22 Wellesley DG, Slaney SF. MURCS in a male? F Med Genet 1995;32:314-15. 